\title{
SOCIOLINGUISTIC PRINCIPLES OF THE MONO-FACTORIAL OR LINEAR CLASSIFICATIONS OF THE LANGUAGES OF RUSSIA
}

\author{
Vida Yu. Mikhalchenko ${ }^{1}$, Elena A. Kondrashkina ${ }^{2}$, Svetlana V. Kirilenko ${ }^{3 *}$ \\ ${ }^{1}$ Prof. Dr., Head Scientific Researcher, Institute of Linguistics, Russian Academy of Sciences, \\ RUSSIA, vida-mi@mail.ru \\ ${ }^{2}$ Senior Scientific Researcher, Candidate of Sciences (Philology), Institute of Linguistics, Russian \\ Academy of Sciences, RUSSIA, e.kondrashkina@inbox.ru \\ ${ }^{3}$ Scientific Researcher, Candidate of Sciences (Philology), Institute of Linguistics, Russian \\ Academy of Sciences; Assoc. Prof., RUSSIA, svetlanavk@inbox.ru \\ ${ }^{*}$ Corresponding Author
}

\begin{abstract}
In the modern world, two controversial trends are observed in the development of languages: on the one hand, it is the desire to expand the social functions of the majoritarian languages; while on the other hand, there are numerous attempts to preserve the language diversity of the world and to support minority languages to the maximum extent possible.

The article analyzes mono-factor, or linear, classifications of the languages of Russia (by the factor of the presence / absence of writing, by the time of appearance of writing, by the number of speakers, by the number of social functions performed, etc.). The classifications, that are based on extra-linguistic features characterizing their speakers, clarify the processes of language functioning and the prospects for the development of languages. The classification of languages according to the above-mentioned classification criteria allows a better understanding of the mechanisms of interaction of two systems, i.e. social and linguistic.

Furthermore, the authors also examine the number of languages of the indigenous peoples of Russia and note the need to consider the languages of the indigenous peoples of Russia to be not only the languages of small peoples, but also the include in the list a wide range of languages which have similar characteristics. Besides, the authors emphasize the importance role of the language policy in safeguarding the vitality of diaspora languages, which are more dependent on the active attitude of the state to their preservation and development than the languages of indigenous peoples.

The paper analyses the new notion 'sociolinguistic portrait'. It is pointed out that it is crucial for language planning policies to single out which languages have a stable social base and the basis for further expansion of social functions, and which languages lack support and are prone to extinction. The correctly composed sociolinguistic portrait of a language helps to forecast the potential for further development, improvement in functional styles, and expansion in the areas of use.
\end{abstract}

Keywords: mono-factorial classification, languages of Russia, sociolinguistic typology, indigenous peoples, languages of indigenous peoples, diasporas, sociolinguistic portrait, language legislation

\section{INTRODUCTION}

Each stage of the historical development of mankind creates certain conditions for the expansion of scientific knowledge. Thus, the high level of development and widespread dissemination of modern technological and informational capabilities in the 21st century creates the preconditions for the transition to a new stage, for new achievements in various branches of modern science. The talk is not about putting forward new 
theories, new hypotheses about the development of language and society, but rather about the technology of collecting material, methods of analyzing and storing it. Being at different levels of development, individual branches of the science of language can use the achievements of technology and advances of IT in different ways.

For any science, such components as theory, conceptual apparatus, methods and information support are important. It is quite obvious that modern technologies help to systematize factual data and present it in the form of language corpora, information systems, databases, and this, in turn, provides new opportunities for understanding linguistic development, the role of language in society, and the relationship between People and their Language.

\section{METHODOLOGY}

Sociolinguistic portrait of a language is a system representation in quantitative indicators of the parameters of social functions of languages. For social linguistics as an interdisciplinary section of science the technological capabilities are of particular importance. Having created a detailed 'sociolinguistic portrait' of a number of languages, social linguistics gets the opportunity to move to the next step, i.e. to analyse 'sociolinguistic portraits' of languages and progress to a new level, i.e. to the typological research and drawing up a functional typological classification languages.

By and large, linguists from all over the world have created different classifications of languages. Traditional classifications of internal linguistics are based on similarities and differences in the internal structure of languages, or on the comparison of genetic parameters, and these classifications usually do not pay enough attention to the social functions of languages. In 1970s the functional typological classification of languages was commonly understood as the categorisation of the world's languages to certain taxonomic areas by the number of social functions they perform (see Yunus D. Desheriev). In accordance with it, all languages of the world can be represented in the form of a pyramid, the basis of which constitute a great number of languages with minimum volume of social functions (the languages of intra-family, everyday communication, traditional economic activities, folklore), and at the top of that there can be found several so-called 'world languages', which serve all areas of communication, including the international one.

Social functions of a language, as we see it, are the functions of a language related to linguistic processes in society, for example, the role of a language as one of the means of ethnic and cultural identification; the use of a language as a means of communication and language integration in a multinational state, etc. Generally speaking, the main general social functions performed by languages in heterogeneous communities are integrating, consolidating, symbolic and separating functions.

The classifications, based on extralinguistic features that characterize their speakers, show the processes of functioning and the prospects for the development of languages. The classification of languages according to the sociolinguistic criteria allows us to better understand the mechanisms of interaction of two systems: social and linguistic, and also deepens our knowledge about the spheres of communication and the results of the influence of extralinguistic factors on the functional development of the language.

When analysing a particular language from a sociolinguistic point of view, it is necessary to enumerate its relations to each of the indicated one-factor classifications. Considering for example, the Tatar language: it is written, old-written, the language of a large people, polyfunctional, state language of the republic, has a high functional status. Such a characteristic of the language gives a general idea of the level of the modern state of the language, and the detailing of its 'sociolinguistic portrait' allows you to go further - to judge its potential for further development, i.e. expand its the social base, improve functional styles, expand the scope of communication areas.

\section{OVERVIEW OF SOME IMPORTANT SOCIOLINGUISTIC PARAMETERS}

The age of writing tradition is a crucial parameter in sociolinguistic classification of language. The time of the appearance writing is one of the important sociolinguistic indicators. It is closely related to the degree of functional development of a language, in particular, with its use in such spheres of communication as education, scientific activity, culture, etc.

In Russian sociolinguistics, a classification of languages was adopted based on the age of writing tradition. Although the time of the beginning and end of the corresponding periods is not always clearly defined, the classification can have the following breakdown:

- Old-written languages; 
- Young-written languages;

- Newly-written languages.

An old written language is any language with a long standing written tradition. In Russian linguistics, it is the language that developed as a polyfunctional one before the beginning of the XX century (e.g. Russian or Tatar languages).

A young-written language the one which used to be an unwritten language in Russia until the XXI - early XX centuries and which received writing system specially created for it. In Soviet times, a writing system was created for more than 50 languages. That was called a period of 'language construction'. During that process a set of state measures were aimed at improving the functional status of the languages: writing system was created, languages were introduced into the education system, into mass communication, etc. In parallel with that, an enormous amount of work was performed targeting to improve the structure of languages, i.e. in the areas of professional terminology, standardization, codification, etc. In 1920s-1930s writing was created for a number of unwritten languages, their alphabets were developed, spelling was improved, dialect bases of literary languages were specified, the norms of literary languages were established, and normative grammars and dictionaries were created. A great number of young-written languages can be found in the Caucasus, for example, Abaza, Lak, Darginsky, Tabasaran, Nogai. Among young-written languages of Russia there are the languages of comparatively large ethnic groups, numbering from over half million people (Mordovian) to $1.1 \mathrm{mln}$ speakers (Bashkir). At the same time there are the languages of minority peoples with under five thousand speakers (Tat, Chukchi, Even, Nanai) and even with fewer speakers, less than a thousand (Eskimo). [Census 2010]

At the end of the $X X$ century, in connection with a new stage of language construction and the appearance of writing in previously unwritten languages, a new concept arose: newly written languages. Therefore, newly written languages are the languages that relatively recently received writing systems (around the 1990s). They are the languages that traditionally functioned in the family and everyday communication spheres, in folklore; with the adoption of writing, their functional load expanded to some areas of regulated communication, mostly into the field of school education (in primary schools). On the territory of Russian Federation newly written languages include the languages of Siberia (in the Krasnoyarsk Territory - Enets, Dolgan, Ket, Nganasan; in the Khabarovsk Territory - Ulch; in the Irkutsk Region - Tofalar; in the Tyumen Region - the Nenets Forest, etc.) and in the Caucasus, especially in Dagestan (Rutul, Agul languages).

\section{SINGLE-LINE CLASSIFICATIONS' ANALYSIS}

When creating sociolinguistic classifications, the main indicators, which are taken into account, are certain external, socio-linguistic parameters: the type of external factors, their impact on languages, groups of languages which possess similar characteristics.

In modern Russian sociolinguistics, simple mono-factorial, single-line classifications of languages are used, which are based on the following factors:

- The factor of the presence or absence of writing, i.e. written and non-written languages;

- The time of the appearance of a writing system, being it an old-written, a young-written, a newly-written, or an unwritten language;

- The number of native speakers (according to the social base); they can be languages of majoritarian peoples, languages of middle-numbered peoples and languages of minorities (less than 50,000 native speakers);

- The number of social functions performed by languages, i.e. languages with maximum social functions, languages with minimum social functions, i.e. monofunctional languages, for example, languages of family communication, single-aul languages (languages of mountain villages), and bifunctional, trifunctional languages can be placed between polyfunctional languages and monofunctional languages;

- The presence / absence of legal status;

- The presence / absence of functional status, i.e. linguistic basis for functioning in a particular area of communication.

Along with the above classifications of the languages of the peoples of Russia, scientific interpretation and classification is required by the entire numerous corpus of languages in Russia, which according to the 2010 census includes 275 languages. However, the following should be taken into account: the number of the 
languages of Russia does not coincide with the number of languages of the indigenous peoples of Russia, 92. Besides, there are much more diasporas' languages.

\section{DISCUSSION}

Let us note, by the way, that such terms as 'people', 'nation', 'indigenous people' in the legal literature do not have a clear interpretation. Thus, discussions about the concept of 'people' in international legal and ethnographic literature are still going on, although it became a subject of international law in 1945 in connection with the consolidation of the principle of 'equality and self-determination of peoples' in the UN Charter. The classification of peoples is carried out taking into account the history and conditions of their development by types (ethnic groups), categories and races. By ethnicity (types), a tribe, nationality and nation will be distinguished, by categories or groups, i.e. indigenous (state-forming or small in number), national minorities, colonial, divided, etc. The attitude to the concept of 'indigenous people' largely depends on the relationship with other words denoting conquests, invasions. In international terminology, the notion 'indigenous people' is understood as an aboriginal, autochthonous, indigenous population. In Russia the term 'indigenous small peoples' is used. These are 61 indigenous small peoples living in the territory of their ancestors' settlement, preserving their traditional way of life, farming and crafts, numbering less than fifty thousand people in the Russian Federation and recognizing themselves as independent ethnic communities [Federal State law 1999]. Often, the rights of indigenous minorities are considered along with the rights of national minorities in the sociolinguistic terminology (that is of diasporas), although national minorities may not live compactly or do not have a number of other features characteristic of indigenous peoples, namely:

- The main feature of indigenous peoples is the historical connection with the territory of their residence:

- Self-perception of having the above-mentioned identity;

- Having their own language, culture, customs, traditions;

- The desire to preserve their land and ethnic identity as the basis for the continuation of their existence as a cultural and linguistic community.

According to the UN definition, the term 'indigenous people' can be applied when speaking of an indigenous ethnos living in a certain territory for over 300 years. According to our observations, an ethnic community does not usually become indigenous people, since in the third generation it usually loses its language, common traditions, as it lives in the zone of active influence of other languages and cultures. At the same time, it is necessary to preserve other characteristics of the people, i.e. a common culture, compact settlement, common traditions, language, self-identification. About 130-135 peoples live in the Russian Federation, 92 of them are indigenous, as their speakers live in their ancestral territories, do not have their historical homeland anywhere else on earth and do not have their own state education at the level of a subject of international law.

It should be considered that the rest of the ethnic communities are national minorities, since the independent states - their historical homelands - can act as the guarantor of their rights. Such, for example, are Germans, Koreans, Lithuanians, Ukrainians, Kurds, Kazakhs, Latvians, etc. For example, Germany has for many years exerted political and economic influence on the Volga Germans, and Russia protects the rights and interests of Russians living in the Baltic countries, Ukraine and the CIS. In social linguistics, such language communities are called diasporas. The language life of such ethnolinguistic communities largely depends on the compactness of their residence, the functioning of the corresponding language in different spheres of communication, as well as on the intensity of support for the country where the development of their language continues. The language of the diasporas themselves functions in conditions of active interaction with the surrounding languages, which at first leads to the formation of a contact variety of this language, and later to the transition among the speakers of this language to speaking another language. Therefore, in our opinion, the talk about three centuries that are necessary to be called indigenous people, according to the UN definition, does not sound reasonable enough. After so many years, a native language in a diaspora will gradually be forgotten, the language will change and the diaspora will merge with another language community, the one of the country's indigenous peoples. Thus, diasporas or national minorities are opposed to the indigenous peoples of Russia: they have their own historical homelands, which, in fact, can be independent states with the status of subjects of international law, their historical homelands can act as guarantors of rights, defenders of their interests.

There is no term 'indigenous peoples' in the Russian legal framework. Instead, the term 'small indigenous peoples' is used. To distinguish the indigenous peoples of Russia in this group, a numerical criterion was introduced, that is more than 50,000 people. However, this approach raises the following objections: 
- the introduction of a numerical criterion contradicts international legal documents, where the numerical criterion is not even mentioned when defining the term "indigenous peoples". In addition, from a legal point of view, when determining the legal personality of a people, the introduction of such a criterion is discriminatory;

- there are contradictions with the traditional sociolinguistic classifications of the languages of Russia, which have long been split into language minorities (minority languages, languages of small peoples - less than 50,000 ) and majoritarian languages (languages of peoples with higher population numbers). These languages differ in the prospects for their further development, which is reflected in their names majoritarian and minoritarian.

\section{ANALYSIS}

The Research Center for National and Language Relations at the Institute of Linguistics, Russian Academy of Sciences, has developed a systematic approach to the languages of Russia, which takes into account 3 large groups of languages: the majoritarian languages of the peoples of Russia, the minority languages of the peoples of Russia and the languages of the diasporas (languages of national minorities).

\section{Classification of languages in Russian Federation}

\begin{tabular}{|c|c|c|}
\hline $\begin{array}{c}\text { Majoritarian indigenous } \\
\text { languages (over 50,000 native } \\
\text { speakers) }\end{array}$ & $\begin{array}{l}\text { Minority languages of indigenous } \\
\text { peoples (less than } 50,000 \text { native } \\
\text { speakers) }\end{array}$ & Diasporas' languages \\
\hline $\begin{array}{c}\text { Abazin, Avar, Adyghe, Altai, } \\
\text { Bashkir, Buryat, Dargin, Ingush, } \\
\text { Kabardino-Circassian, Kalmyk, } \\
\text { Karachay-Balkarian, Karelian, } \\
\text { Komi, Komi-Permian, Kumyk, } \\
\text { Lak, Lezghin, Mari, Mordovian, } \\
\text { Nogai, Ossetian, Tabasaran, } \\
\text { Tatar, Tuvin, Udmurt, Khakass, } \\
\text { Chechen, Chuvash, Yakut, } \\
\text { Russian (30) }\end{array}$ & $\begin{array}{c}\text { Aleutian, Alyutor, Andi, } \\
\text { Archinsky, Akhvakhsky, } \\
\text { Bagvalinsky, Bezhtinsky, } \\
\text { Botlikhsky, Vepsian, Votsky, } \\
\text { Ginukh, Godoberin, Gunzib, } \\
\text { Dolgan, Izhora, Itelmen, } \\
\text { Kamchadal, Karatin, Kaitag, } \\
\text { Kerek, Ket, Koryak, Kubachin, } \\
\text { Kumandin, Mansky, Nanai, } \\
\text { Nganasan, Nenets tundra and } \\
\text { forest, Nivkh, Uilt, Oroch, Rutul, } \\
\text { Sami, Selkup, Soyot, Taz, Tati, } \\
\text { Telengit, Teleut, Tindal, Tofalar, } \\
\text { Tubalar, Udege, Olcha, Khanty, } \\
\text { Khvarshi, Tsakhur, Tsez, } \\
\text { Chamal, Chelkan, Chuvan, } \\
\text { Chukchi, Chulym, Shor, Even, } \\
\text { Enets, language of the Asian } \\
\text { Eskimos, Yug, Yukaghir (62) }\end{array}$ & $\begin{array}{l}\text { Armenian, Azerbaijani, Afghani, } \\
\text { German, Korean, Chinese, } \\
\text { Kazakh, Latvian, Lithuanian, etc. }\end{array}$ \\
\hline \multicolumn{2}{|c|}{92 languages of indigenous peoples in Russian Federation } & $45-50$ languages \\
\hline
\end{tabular}

When creating major works on the sociolinguistic analysis of the language life of Russia, this classification of the languages of Russia was applied, which we consider consistent and historically fair. In total, according to our calculations, there are 92 indigenous languages in Russia and a number of diaspora languages. Of course, it is necessary to provide support for the languages; create favorable conditions for the languages of small peoples, whose cultural treasures, a special way of life, a peculiar language picture of the world are a world heritage and should be preserved as part of a common human culture. However, other peoples of Russia, their cultures and languages are worthy of recognition, support, and there is not a dichotomy between indigenous and non-indigenous peoples. After all, the Constitution of the country begins with the words - 'We, the multinational people of the Russian Federation', therefore all peoples (ethnic groups) of the country have the right to be called indigenous, since they live in their ancestral territories, nowhere on the Earth do they have their own historical homeland or their state formation [Ruslan Sh. Garipov]. The point here is only in legal nuances, especially since many of the titular ethnic groups and a number of other indigenous ethnic groups of the country are fixed in the current language legislation, although, unfortunately, their functional status often does not correspond to the legal one and creates the need for further improvement of different levels. 
Why do we consider it fundamentally important to clarify the classification of the languages of Russia in the field of distinguishing the languages of indigenous peoples and differentiate them from other languages? The fact is that such a classification is important for the conscious impact of society on the language through forecasting and planning for further development, improving the language life of a multiethnic country. Only a scientifically substantiated identification of the languages can contribute to the rational planning of the social functions of different groups of languages, the allocation of appropriate resources from the country's budget in connection with the use of languages in different spheres of communication: in school education, in print, on the radio, on television and in other areas of organized communication. When planning, the state authorities should understand which languages have a social base, the basis for further expansion of social functions, and which languages need support due to the danger of their extinction. In addition, it is necessary to understand that the languages of the indigenous peoples, in comparison with the languages of the diasporas, are more dependent on the active attitude of the state towards their preservation and development than the languages of the diasporas.

Diaspora languages only function to one degree or another in certain compact language communities. They can disappear in the life of such communities, especially since they are usually subjected to social pressure from the languages of other, neighboring languages, which are more numerous in speakers and more powerful in terms of social functions. This can lead to the language death in a given community, to a functional transition to another language, but the language itself does not disappear, since it functions and develops in the country of origin. The cultural and language life of the diaspora is regulated by the law on cultural autonomy, which guarantees the right of diasporas to learn their native languages and to function in accordance with the social needs of the diaspora. These rights are put into effect to a large extent at the expense of the state of residence, since the overwhelming majority of members of the diaspora are the citizens of Russia, they work here, and pay taxes. On the other hand, the law allows receiving support from the state for these language communities, where most native speakers live, and its functional development takes place. That is why diaspora languages are not included in the databases on the endangered languages of the world and the well-being of such languages is usually associated with the degree of mobility, cohesion, adherence to the native culture and language of a particular language community, a separate language community. In is important to note, incidentally, that a number of diasporas (national minorities) in Russia has not been sufficiently studied yet, therefore it is difficult to accurately calculate the number of languages in Russia ( $\approx 140-150)$.

\section{CONCLUSION}

In the modern world, there are two trends in the development of the world language process: the desire to expand the social functions of the majoritarian languages, on the one hand, and, on the other hand, the attempt to preserve the language diversity of the world, to support the languages of minorities. For a rational combination of these two trends in the language policy of a multi-ethnic state, it is necessary to have a good understanding of the language problems of the country and take them into account when adopting laws on languages, language development programs for the sake of improving and harmonizing the language life of the country.

\section{ACKNOWLEDGEMENT}

The reported study was funded by RFBR and DFG, project number № 21-512-12002 HHИO_a "Prognostic methods and future scenarios in language policy - multilingual Russia as an example"

\section{REFERENCE LIST}

Dictionary of Sociolinguistic Terms (2006) / Mikhalchenko,V.Yu. (ed.) Moscow: Institute of Linguistics, Russian Academy of Sciences.

Federal law of 30.04.1999, No. 82FZ 'On guarantees of the rights of the indigenous peoples of the Russian Federation' // Code of laws of the Russian Federation No. 18. Moscow.

Garipov, R.Sh. (2013) The concept of 'indigenous people' and their status in international and national law. International law and international organizations, p. 408-420, DOI: 10.7256/2226-6305.2013.3.5362

Human and Peoples' Rights (2006). / Edited by O.O. Mironov. Saratov.

International public law (2004) / Edited by G.I. Kurdyukov. Kazan. 
Language and Society. Encyclopedia (2016). Moscow.

Language policy in the context of modern language processes (2016). Moscow.

The results of the 2010 All-Russian Population Census: in 11 volumes (2012). Vol. 4, book 1.Moscow.

Written languages of the world. Languages of the Russian Federation (2000). Book 1. Moscow.

Written languages of the world. Languages of the Russian Federation (2003). Book 2. Moscow.

Yunus D. Desheriev (1976) Social Linguistics: to the foundations of the general theory. Moscow. 